\title{
Gilberto Freyre: alguns comentários sobre o contexto bistoriográfico de produção de Casa grande e senzala Angela de Castro Gomes*
}

Quase sempre, quando se fala de Gilberto Freyre e de seu primeiro e consagrador trabalho - Casa grande e senzala -, cuja primeira edição é de 1933, menciona-se uma hoje célebre apreciação de Antonio Candido que coloca este ensaio histórico-sociológico, ao lado de dois outros, como um dos marcos de uma grande ren ovação no pensamento social brasileiro. Os dois textos que co mpõem com Casa grande esta espécie de trilogia muito especial são Evoluşão politica do Brasil, de Caio Prado Júnior, também de 1933 e Raizes do Brasil, de Sérgio Buarque de Holanda, de 1936. Aliás, é no prefácio deste último livro que Antonio Candido argumenta como esses autores e obras transformaram o campo da literatura que interpretava o Brasil em meados dos anos 30 , contribuindo decisiva e definitivamente com suas inovações. Nesse sentido, ele assinala o impacto que produziram pela utilização de novas fontes e pelo uso de orientações teóricas e metodológicas, até então pouco conhec idas e praticadas. Logo, nas contextualizações que se faz da mais famosa obra de Freyre, o que se privilegia é o período dos anos 30 e inícios dos 40 , recorrendo-se a aproximações com autores mais identificados com uma tradição do pensamento sociológico bras ileiro, guardando-se os cuidados com esta terminologia.

Meu objetivo neste artigo, é realizar algo um pouco difere nte, procurando pensar o contexto de produção de Casa grande, recuando pouco mais o ângulo de visão no tempo e caminhando para as conturbadas décadas de inícios do século XX. Com a mesma finalidade, desejo estabelecer um diálogo entre Freyre e outros a u- 
tores e tipos de obra, para com isso ganhar uma nova perspectiva sobre o momento de recepção do famoso livro. Nesse sentido, o diálogo construído por mim é uma possibilidade de aproximação para se entender algumas das características do campo intelectual das primeiras décadas do século XX e não propriamente um exe rcício de comparação, que seria equivocado e infrutífero. No caso, o que mais me interessa é centrar a visão na área dos estudos de História do Brasil, que começava a se autonomizar dentro da pr odução mais global de estudos sobre a sociedade brasileira, busca ndo desenhar o que era próprio do historiador e portanto, vendo-o em relação e em distinção ao geógrafo, ao sociólogo, ao etnólogo, ao folclorista, ao literato, etc. Isto, evidentemente, com os embates e a fluidez de fronteiras que momentos inaugurais de construção de identidades possuem, havendo sempre a óbvia possibilidade das mesmas pessoas acumularem mais de um papel.

Realizar esse tipo de deslocamento para mim é importante, porque considero haver um misto de desconhecimento e desint eresse sobre as primeiras décadas do século $\mathrm{XX}$, justamente aquelas em que os intelectuais sofreram o impacto da experiência republ icana, que se seguiu a do fim do regime escravista. No campo da história, esse período costuma ser entendido, muito a grosso modo, como marcado pela produção de uma literatura histórica de cunho positivista, quer dizer, uma literatura centrada no fornecimento de informações-enumerações (fatos, nomes e datas), que privilegiava tão somente aspectos políticos e administrativos de nossa história nacional.

Meu interesse, por excelência, é o de problematizar esse período, situando de forma mais cuidadosa o contexto político e i ntelectual que emoldura a produção historiográfica que antecede ou convive com os primeiros trabalhos de Freyre. Não se trata, po rtanto, nem de maximizar nem de minimizar sua obra, mas apenas estabelecer algumas observações que podem ser interessantes para 
se entender melhor como se desenvolviam os principais debates na época e o que eles envolviam de fundamental.

Para tanto, no caso da história, o lugar-chave - política, soc ial e academicamente - onde tais debates ocorriam, era o Instituto Histórico e Geográfico Brasileiro, o IHGB. Esta instituição, criada em 1838 e voltada para a construção de uma história e memória nacionais, vivera sempre sob a proteção direta do Imperador. Por conseguinte, fora muito afetada, em seu prestígio e em seus cofres, com o fim da Monarquia. Embora integrada por numerosas pers onalidades francamente críticas à República, o IHGB entendeu, com alguma rapidez, que precisava se adaptar aos novos tempos, inic iando grandes esforços para se recompor tanto organizacionalme nte, quanto intelectualmente. Estes esforços cobrem principalmente os anos que vão de 1908 a 1938, quando o Instituto é presidido por dois importantes nomes da cultura e da política no país: o barão do Rio Branco (até 1912, quando morre) e conde Afonso Celso (desde então até 1938).

Ao longo desses trinta anos, pode-se constatar, no interior do IHGB, como se articula um investimento político e acadêmico de peso, que redireciona a produção da história e da memória nac ionais. De um lado, tratava-se de conferir à literatura histórica um papel político central para o novo regime, o que significava que ela precisava adquirir outras características, mais conformes aos te mpos da República. De outro, fica claro como os membros do IHGB se dispõem a enfrentar um elenco de questões primordiais para o campo intelectual de inícios do século, entre as quais ressalto apenas duas, por sua importância e relação com a obra de Freyre.

A primeira, é a fundamental questão da "formação do povo brasileiro", que remete a Von Martius e a seu trabalho, Como se deve escrever a História do Brasil. Ela tradicionalmente envolvia o lugar do português, do índio e do negro no curso de nossa "evolução" como povo e nação. Contudo, após a abolição e a República, foi 
ficando evidente que tal trilogia necessitava de uma certa revisão. Ou seja, que esses atores da História do Brasil precisavam ter suas posições e colaborações repensadas, inclusive porque a "questão racial" ganhava novos contornos com o fim da escravidão, o que fazia com que os debates intelectuais e propostas políticas que a envolviam, assumissem outra intensidade e também novas nuances, em particular no que se referia aos índios e negros. Nesse sentido, o que quero destacar é que, ao lado do amplo compartilhamento das teorias européias racistas que existia na virada do século $\mathrm{XX}$, crescem as divergências quanto a avaliação dos efeitos da miscig enação existente no Brasil, francamente constatada, mas nem se mpre mais tão condenada. Continuava-se a acreditar na existência de bases científicas para tal teoria, o que com certeza era uma das fortes razões para o sucesso da ideologia do branqueamento, mas começava-se a ponderar de forma mais evidente sobre a presença ativa de índios e negros em nossa história e cultura. Para isso, basta lembrar o nome de três intelectuais que contestavam a visão dom inante na época: Alberto Torres, Manuel Bonfim e Edgard Roqu ette Pinto.

A segunda é a questão que pode ser identificada como a dos inícios da "invenção de uma tradição política republicana" para o Brasil. Questão complexa e delicada, que devia levar em conta no sso passado colonial - cuja importância não estava sendo minimiz ada-, mas que devia também considerar nosso passado imperial, o que evidentemente implicava correr alguns riscos, sobretudo nas duas primeiras décadas republicanas: anos de militarismo, de jac obinismo e de perseguições políticas. Com seu próprio passado tão vinculado à monarquia e ao monarca, o desafio que se colocava para o IHGB era tornar palatável a convivência entre Império e República, sem desmerecer as tradições do primeiro e sem ferir o desejo de construir uma nova tradição política, acalentada pela s egunda. Mais do que isso, tratava-se de o próprio Instituto engajar- 
se nesse propósito, com habilidade e prudência, que não faltaram a um barão e a um conde convertidos aos novos tempos.

Os debates que agitaram o IHGB nesse período abarcam, além do que se pode considerar as novas questões substantivas da conjuntura política, também uma série de outras preocupações particularmente interessantes para os objetivos desse artigo. Eles envolveram toda uma discussão sobre a própria natureza do texto histórico, dando destaque a alguns pontos específicos, que nos e sclarecem sobre o tipo de produção que estava sendo conceituada como de "história moderna". De modo muito sucinto e correndo o risco de esquematismos, tais pontos seriam os seguintes:

- a natureza e o uso de fontes no trabalho de pesquisa hist órica;

- o método de pesquisa, considerando-se que a "exposição" dos acontecimentos precisava ser pautada pela apresentação e pela crítica do material documental levantado;

- e a "interpretação", situada como um momento integrante do trabalho do historiador, entendendo-se que ela abarcava o duplo esforço de se "narrar" os fatos e de se buscar o "sentido" desses mesmos fatos. Desta forma, o historiador tinha o compromisso de "mostrar" esse sentido ao leitor, em especial quando ele fosse um público escolar.

O historiador, nestes termos, começava a ser crescent emente definido e reconhecido como um profissional que era capaz de:

a) localizar, selecionar e classificar documentos, pois os "fatos" com que ele trabalhava eram reais (e assim se distinguia prioritar iamente do literato);

b) entender que era através destes procedimentos metodológ icos que se baseava a "verdade" dos fatos que iria narrar, ou seja, que nestes procedimentos estava o fundamento e, digamos, a nat ureza de sua "neutralidade"; 
c) e "interpretar" os fatos, isto é, ser capaz de estabeler um sentido, uma lógica para a história que narrava. Esta interpretação era claramente entendida como fruto do trabalho intelectual do historiador, um homem de "seu" tempo que, com as preocupações que lhe eram contemporâneas, "ordenava - dava sentido" ao tempo histórico. O historiador, portanto, estava sendo visto como um homem que - independentemente de sua vontade pessoalindividual - ligava-se a um certo conjunto de interesses e possibilidades do tempo que vivia e sob cuja influência escrevia a história.

É através desse longo e delicado debate, que é possível ver ificar uma série de características que começam a ser ressaltadas, por vários críticos da época, como essenciais para se escrever uma obra considerada inovadora no campo da história. São apreciações muito esclarecedoras para se perceber o que então estava sendo produzido e consagrado neste terreno. Apreciações que indicam a formação de uma certa tradição historiográfica em nosso país, que cresce e se reforça até os anos 40 , aproximadamente, para se ob scurecer, a meu juízo, principalmente no decorrer dos anos 60 .

Para dar concretude ao que se quer apontar, sem cansar com a multiplicação de exemplos, alguns livros podem ser destacados como símbolos do que de melhor se fazia na época, segundo os mais severos e conceituados comentaristas. Entre eles pode-se enumerar: Um estadista no Império: Nabuco de Araújo, de Joaquim Nabuco, publicado em 1898; História do Brasil, Curso Superior, de João Ribeiro, de 1900, ano em que se comemorava os 400 anos do De scobrimento do Brasil; D. João VI no Brasil, de Oliveira Lima, editado em 1908, ano do Centenário da Abertura dos Portos do Brasil; e Vida e morte do bandeirante, de Alcântara Machado, bem posterior, pois lançado em 1929.

E o que esses livros traziam de novo e de especial para a literatura histórica, na ótica dos críticos que intermediavam sua 
recepção? Um não tão breve comentário de José Veríssimo, uma espécie de monstro sagrado da crítica de inícios do século, pode ser pedagógico. Saudando o livro de Joaquim Nabuco, que para ele abria um precedente na nossa descurada e pouco sabida história, escreve:

'Uma das coisas que faltam à nossa história - e quase tudo lhe faltasão os documentos intimos, as memórias, as correspondências. Sem tais subsidios é impossivel conbecer bem a fisionomia de uma época ou de uma personagem. À bistória feita apenas com documentos oficiais, por sua mesma natureza impessoais e incaracteristicos, falha forçosamente a vida, que só lhe pode vir dos elementos que permitam reconstituir a feição das coisas e dos bomens pelo estudo psicológico destes e do meio em que viveram. Esse estudo é impossivel sem aqueles documentos privados e apenas com socorro dos monumentos burocráticos e oficiais. Dai a insipidez geral da nossa bistória, que tem a secura e o incolorido de um relatório. (...)

Com esse material escreveu o Sr. Joaquim Nabuco este livro, que graças a esses papéis intimos, além dos documentos oficiais (...) tomou uma feição distinta na nossa literatura bistórica. Se a narrativa se apoia principalmente nas fontes oficiais, são evidentemente os documentos de intimidade, correspondências, notas, reminiscências da família e dos amigos, recordaçòes do próprio autor, que animam e vivificam os homens de estado, políticos, jornalistas, revolucionários, administradores que nela figuram e cujas feições morais e politicas o Sr. J. Nabuco traça talvez, em alguns ao menos, com mais babilidade de artista que exatidão de fotográfo. (...)

O livro do Sr. Joaquim Nabuco é assim, mais que a vida de seu pai, a exposição da sua época, quase uma bistória do segundo reinado. (...)’”

Não se trata aqui de elencar apreciações, mas de utilizar a sensibilidade crítica de José Veríssimo para melhor detectar as transformações que estavam sendo empreendidas e elogiadas como necessárias, altamente positivas. 
A primeira delas era a de como esses novos textos rompiam com a hegemonia de uma história político-administrativa do Brasil. De como dimensões sociais e culturais as mais diversas se integr avam, harmoniosamente e com grande destaque, às obras históricas que estavam sendo lançadas. De como diversos autores passavam a se interessar por métodos e categorias da sociologia, da antropol ogia, da etnologia, da psicologia e da geografia, guardadas a fluidez entre as fronteiras de saberes que estavam se constituindo e se di stinguindo, sobretudo no Brasil. Por essa razão, como categorias como "formação" e "organização", que trazem nitidamente a idéia de "processo" e de "construtivismo" (não de voluntarismo ou de determinismo) para a história, passavam a ser cada vez mais utiliz adas. Como a própria categoria de "espaço geográfico" começava a ser tratada como algo que não era "natural", sendo entendida como uma dimensão integrante do "social". Quer dizer, como nesse momento se fazia uma história do povo e do território brasileiros indissociavelmente. O "tempo" e o "espaço" eram postulados como construções humanas, e se o meio-espaço influía no curso da vida dos homens, estes também alteravam e influíam no meioespaço, não havendo uma determinação unilateral nessa relação.

$\mathrm{Na}$ mesma linha de reflexão, como se precisava e se devia explorar uma grande diversidade de fontes documentais no trab alho historiográfico. Como a documentação oficial era necessária, mas não suficiente para se escrever uma história atraente que, como diz Veríssimo, não se assemelhasse a um mero e burocrático relatório. É o que havia feito J. Nabuco, mas não apenas ele. $\mathrm{Ol}$ iveira Lima, com o seu $D$. João VI, é fartamente elogiado pelo uso de documentos visuais, como telas, e pela qualidade de sua narrat iva, que "pinta" a ambiência da cidade do Rio de Janeiro e as m udanças que sofreu no tempo em que abrigou a corte portuguesa. Com isso, ambos os livros traziam para o leitor o clima de uma 54 cidade em inícios do século XIX e o de um engenho de açúcar do 
nordeste, ao longo de um bom período de tempo. No caso de A 1cântara Machado, sua formação jurídica é enaltecida pelos frutos que proporciona ao trabalho do historiador. Sua pesquisa, consid erada fantástica e absolutamente original, com inventários e test amentos, lhe permitira traçar a vida cotidiana dos paulistas nos s éculos XVII e XVIII, demonstrando como aquela sociedade era simples e mesmo pobre, desfazendo idéias de grandeza, arraigadas até então. Mas ao contrário do que se poderia julgar, a pesquisa do historiador longe de enfraquecer, aumentara a força do mito ba ndeirante, dimensionando as reais condições do meio físico e social no qual traçou seu caminho pelo Brasil. Enfim, de como todos esses historiadores, no trato com novas fontes e com o uso de n ovas categorias, apresentavam uma história de homens vivos e int eressantes para o leitor. Homens que se comportavam conforme as circunstâncias em que viviam e que faziam escolhas em função de ssas mesmas circunstâncias.

Era justamente isso que faltava ao leitor e que tornava a lit eratura e sobretudo o estudo da História do Brasil tão desintere ssante e desprovido de sentido. Era preciso mergulhar nos arquivos existentes no Brasil e no exterior para se realizar um trabalho cu idadoso de localização e divulgação de fontes documentais, o que devia continuar sendo preocupação do historiador. Mas esta incu rsão não podia perder de vista o objetivo básico da história que era, como se dizia no IHGB, dar um sentido ao tempo, e não ficar re strita a uma enumeração de fatos, datas e nomes.

Exatamente devido a esse tipo de compreensão, o trabalho do historiador precisava passar a destacar o que então se chamava uma "história interna" do Brasil, na terminologia de João Ribeiro. Era uma história que não mais privilegiava apenas os eventos que se desenrolavam no eixo com a metrópole e a corte portuguesa (história externa), mas que devia se dedicar à compreensão dos $\mathrm{f}$ atos que ocorriam "dentro" do país. Para tanto, se a contribuição 
dos portugueses era básica, também eram fundamentais as "contr ibuições" do índio e do negro, em aspectos que envolviam a língua, a alimentação, a música e as danças, por exemplo. Os historiadores e folcloristas, que por vezes se confundiam na mesma pessoa e interesses, investigavam crescentemente tais aspectos, consid erandoos parte de nossa cultura nacional. Tal avaliação, contudo, não el iminava de maneira alguma uma visão generalizada que hierarquiz ava as "raças" que compunham nosso povo, mas sem dúvida ass inalava certas mudanças de valoração em relação a uma literatura produzida anteriormente no próprio IHGB e em outras institu ições, que ignorava quase que completamente a presença positiva de índios e negros.

Enfim, esse breve artigo buscou apenas ressaltar como Casa grande e senzala, de Gilberto Freyre, publicado em 1933, vai enco ntrar, no campo da produção historiográfica, todo um debate e uma prática de trabalho que já conhecia e valorava muitas de suas contribuições. Como, voltando-se às primeiras décadas do século, pode-se detectar a constituição de um clima favorável à recepção do livro, no que diz respeito ao uso de fontes, às características da narrativa, e a uma franca presença de atores vivos, entre os quais se incluía o negro. De como a modernidade de Freyre pode ser enr iquecida com confrontos com a literatura mais especificamente histórica e de como tal confronto pode iluminar a riqueza do ca mpo intelectual que pensava o Brasil na primeira metade do século $\mathrm{XX}$.

E apenas para concluir, é interessante observar como o ve rdadeiro boom de estudos sobre história colonial dos anos 80 e 90 centrado nas dimensões do cotidiano, da religiosidade, da sexual idade, etc -, tem muito a ver com tudo isso. Os 500 anos de Desc obrimento do Brasil e o centenário de nascimento de Gilberto Freyre podem assim ser estímulos valiosos para uma reflexão crít i- 
ca que retome as tradições do pensamento social brasileiro, espec ialmente nossa tão esquecida tradição histori ográfica.

\section{Notas}

* Angela de Castro Gomes é Professora Titular de História do Brasil da Universidade Federal Fluminense e Pesquisadora do CPDOC da Fundação Getúlio Vargas. Este texto foi escrito para ser apresentado oralmente no Ciclo de palestras sobre o pensamento de Gilberto Freyre, ocorrido no Centro Cultural Banco do Brasil, entre 28 e 31 de março de 2000, em comemoração ao centenário de nascimento do autor. Por essa razão, mantém suas características originais de linguagem e tamanho. Agradeço portanto o convite para sua publicaçào, respeitando-se a minha impossibilidade de alterá-lo.

1 José Veríssimo, “Um historiador político: o Sr. Joaquim Nabuco”, Estudos de literatura brasileira, $1^{a}$ série, Belo Horizonte, Ed. Itatiaia; São Paulo, EDUSP, 1976, p. 99, 100, 102. 